$\underline{\text { Iranian Journal of Pathology }}$ | ISSN: 2345-3656

\title{
Aggressive Fibromatosis, Clinicopathologic Findings of 25 Cases; A Single-Center Experience and Review of the Literature
}

\author{
Bita Geramizadeh $^{1,2 *}$, Fateme Jalali ${ }^{2}$ \\ 1. Dept. of Pathology, Shiraz University of Medical Sciences, Shiraz, Iran \\ 2. Transplant Research Center, Shiraz University of Medical Sciences, Shiraz, Iran
}

\begin{tabular}{l} 
KEYWORDS \\
\hline Aggressive fibromatosis \\
Single center experience \\
\\
Article Info
\end{tabular}

Received 12 Oct 2015;

Accepted 26 Feb 2016;

Published Online 29 Jan 2017;

\begin{abstract}
Background: Aggressive fibromatosis is a rare benign tumor with no potential for metastasis; however, its aggressive nature causes treatment failure and episodes of recurrence. There is no report from Iran about the treatment of this tumor, and all published articles are single-case reports, therefore in this study, we report our experience from two of the largest referral centers of the South of Iran.

Methods: During five years (2007-2011), among more than 20000 surgical pathology specimens, 25 cases of fibromatosis were identified. Clinicopathologic findings were recorded for all of the cases, and follow up history according to the patients' charts and direct contact by phone call were extracted.

Results: There were 25 cases of fibromatosis, with female predominance, especially in the reproductive ages. All of the tumors had been located in the abdominal area, lower extremity, and head and neck area. Twenty-three cases had been operated for surgical excision. Fifteen cases had at least one episode of recurrence, mostly located in the abdominal area. No death or metastasis occurred.

Conclusion: Clinicopathologic findings of desmoid tumor in Iran are very similar to other countries, however, there is still much controversy about the method of treatment for fibromatosis, and there are many challenges for patients, regarding multiple episodes of recurrence and the infiltrative aggressive nature of fibromatosis.
\end{abstract}

Corresponding Information Dr. Bita Geramizadeh; Dept. of Pathology, Shiraz University of Medical Sciences, Shiraz, Iran. Tel: 00987136474331 Email: geramib@gmail.com

Copyright () 2016, IRANIAN JOURNAL OF PATHOLOGY. This is an open-access article distributed under the terms of the Creative Commons Attribution-noncommercial 4.0 International License which permits copy and redistribute the material just in noncommercial usages, provided the original work is properly cited.

\section{Introduction}

Aggressive Fibromatosis, known as desmoid tumor, refers to a group of tumors, which arise from musculoaponeurotic structures (1). These tumors were first described in 1832 by MacFarland, in the abdominal wall of a young lady. However, the term desmoid tumor was first used in 1838 by Muller, extracted the word "Desmo", which means tendonlike in Greek (2).

Its annual incidence is 0.2-0.5/100000, and constitutes less than $4 \%$ of all soft tissue tumors (3).
There are a few studies regarding the experiences of different centers with this type of tumor; in this report, we describe our

clinicopathologic experience from two large referral hospitals in the South of the country, with 25 cases of fibromatosis, among more than 20000 pathology specimens, during 5 years (2007-2011).

\section{Materials and Methods}

In this retrospective cross sectional study, there were 25 cases of fibromatosis, operated and followed up for at least 3 years at two large referral centers of the South of Iran. 
All of the demographic, clinical, paraclinical, and surgical information were extracted from the patients' charts; however, for the evaluation of recurrence and other information, for which charts were not adequate, patients were directly contacted by phone.

In these 25 patients, the age range was 2 months to 68 years, with a mean age of 32.9. The mean age for males was 28.4 and mean age of females was 36.6 years. There were 14 females and 11 males $(\mathrm{F} / \mathrm{M}=1.27 / 1)$

\section{Results}

From 25 cases, $56 \%$ were female (14 patients) and $44 \%$ were male (11 patients).

Fifteen cases $(60 \%)$ had tumors that were extraabdominal in the extremities, head, and neck, i.e. 11 tumors were located in the lower extremities, and 4 tumors in the head and neck area, and no tumor in the upper extremities.

Ten cases $(40 \%)$ had tumors that were in the abdominal area, 6 in the abdominal wall and 4 in the intra-abdominal or in the retroperitoneal area.

Size of the tumors was between 3 and $25 \mathrm{~cm}$; the largest tumor was located in the retroperitoneum, measuring $25 \mathrm{~cm}$ in diameter; the mean size was $7.24 \mathrm{~cm}$.

Overall, 44\% of patients (11 cases) were females and in the reproductive age (15 to 45 years of age).

Eight patients had positive family history of fibromatosis and one case (31 year-old male) was a known case of Familial Adenomatous Polyposis (FAP) with a huge intra-abdominal desmoid tumor, and despite resection and multivisceral transplantation, he had several episodes (at least 3) of recurrence.

All of 25 patients, except one case, were symptomatic, and two of the most common symptoms were palpable mass and pain. Three cases presented abdominal pain and intestinal obstruction secondary to intra-abdominal mass. One case had been incidentally diagnosed during sonography for pregnancy.

All of the patients, except two cases were treated with surgery and excision of the tumor. Two patients had huge tumors with extensive adhesion, so they were inoperable. One of them was a 47- year-old male with a huge retroperitoneal mass and severe adhesion to the bladder, for whom surgery was not performed. The other patient was an 18year-old young female, with large thigh mass with extensive adhesion to peripheral nerves and vessels, and the only treatment option was lower limb amputation, which was refused.

Eleven (44\%) patients had one episode of recurrence; one patient had two episodes of recurrence and one patient had three episodes of recurrence in the follow up period. Two patients still have tumors, with no change in size during the past 2 years. Ten patients had no recurrence during the follow up period ( 3 to 10 year). Mean age of recurrent cases was 30.2 with mean size of $9.66 \mathrm{~cm}$. Most of the recurrent cases ( 9 cases) had tumors located in the abdominal area.

Among these 25 patients, 23 were operated, 3 of which had a positive surgical margins. All of the 3 tumors with positive surgical margin have recurred. There was no death during the study period.

Figure 1 and 2 show gross specimens of two cases of fibromatosis. Figure 3 and 4 show microscopic sections of two cases of fibromatosis. Figure 5 shows positive beta-catenin, which is a diagnostic immunohistochemical marker for fibromatosis.

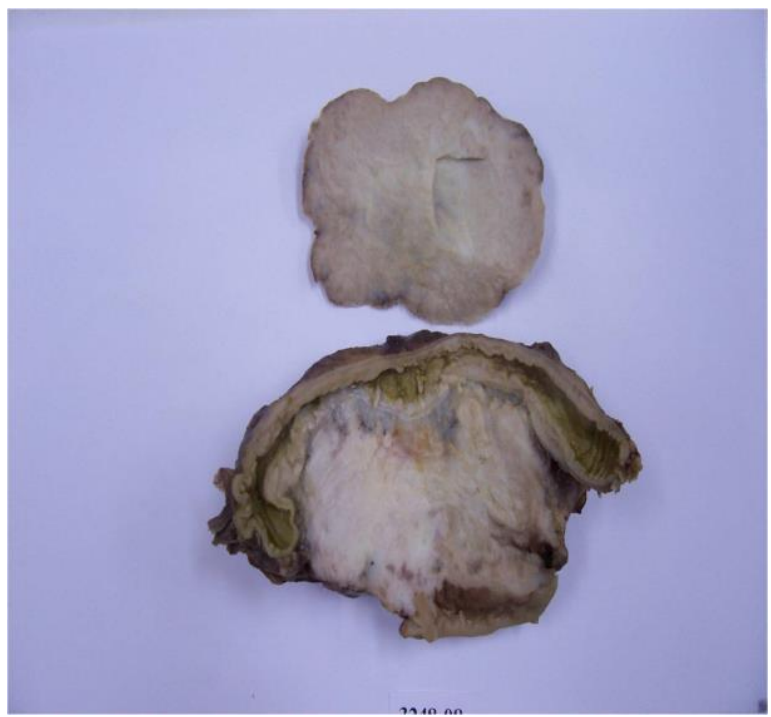

Fig 1. Pathology Specimen of an Abdominal Fibromatosis in the Wall of the Intestine 


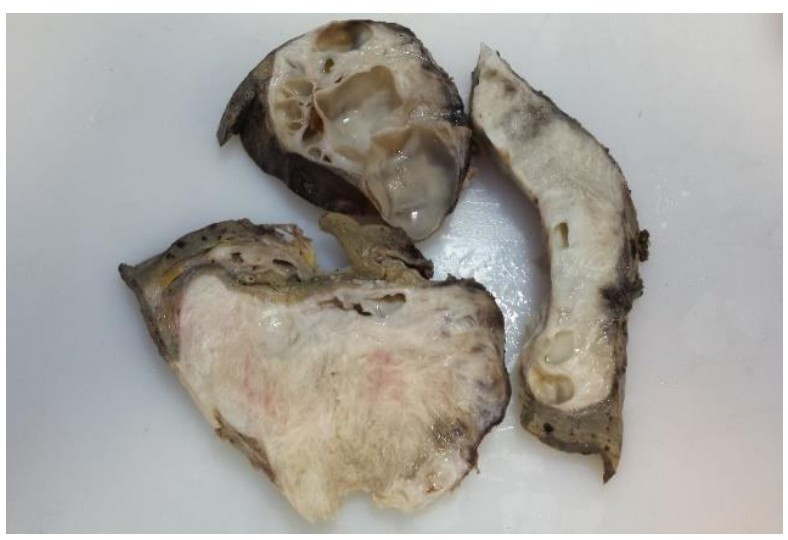

Fig 2. Pathology Specimen of an Abdominal Fibromatosis with Liver Involvement

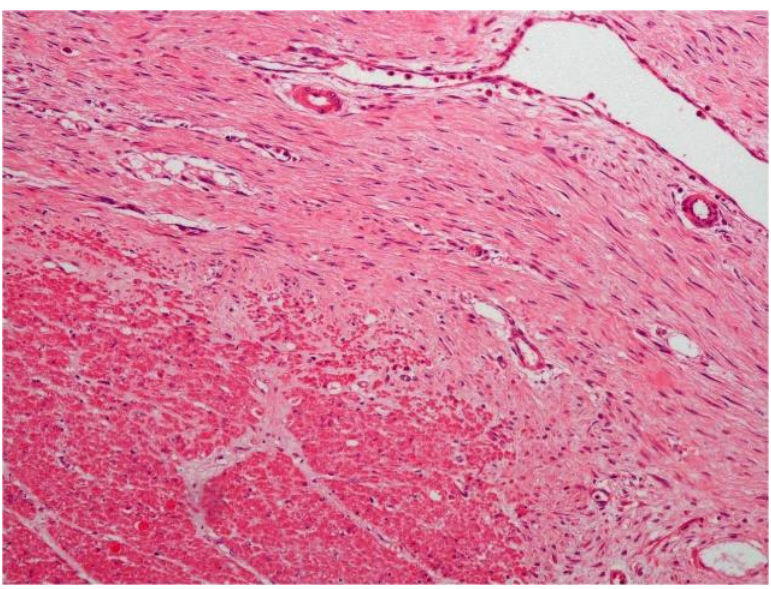

Fig 3. Muscle of Gastrointestinal Wall with Infiltrative Fibromatosis

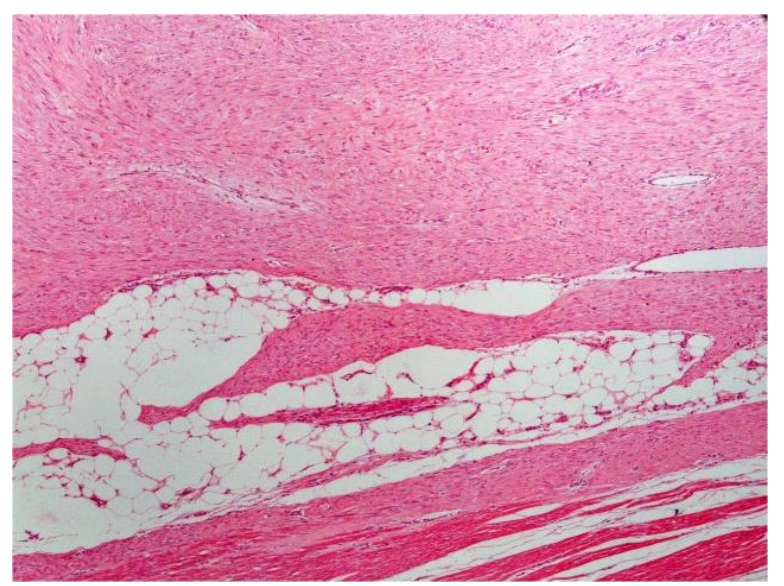

Fig 4. Characteristic Spindle Cell Tumor with Typical Small Arterioles and Abnormal Veins in Fibromatosis

\section{Discussion}

Aggressive fibromatosis, also known as desmoid tumors, can be seen at any location of the body; however, the abdomen, including abdominal wall, retroperitoneum and intra-abdominal, as well as soft tissues of the extremities, shoulder, neck and chest wall are sites of predilection $(4,5)$. These are rare fibrous tissue proliferations with a tendency for slow, local infiltrative growth. They have an association with Gardner's syndrome and FAP (6). Histologically, they are composed of spindleshaped cells with bland nuclei and no abnormal mitoses or necrosis. They do not metastasize, but can cause significant morbidity through their locally infiltrative effects and recurrences (7).

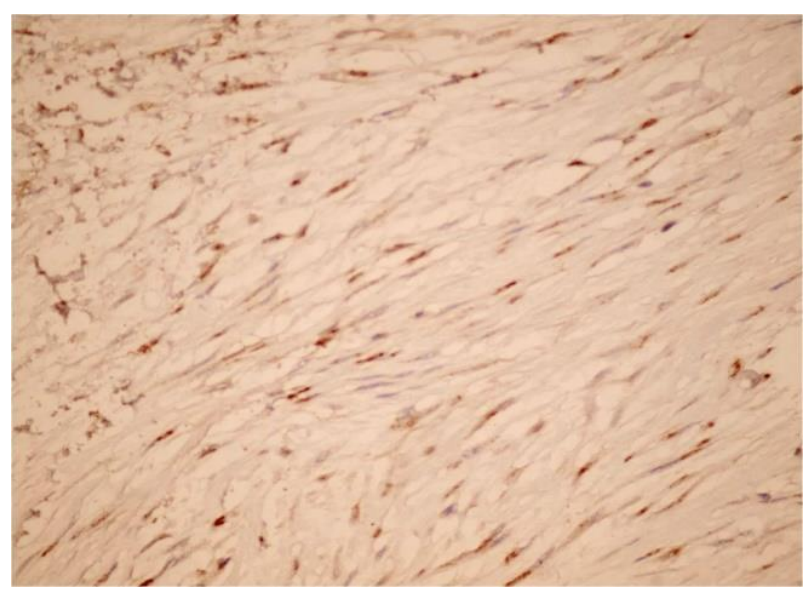

Fig 5. Immunohistochemistry of Positive Nuclear Beta-Catenin

According to the age of presentation, there are two peaks in incidence among individuals aged 6 to 15 years old and between puberty and 40 years old in females (8). During our study, in 5 years, we had the same results and our patients were between 2 months and 68 years old.

This tumor is more common in females, which in agreement with our findings, with a predilection for reproductive age. A study from Italy had very similar findings to that of the current study, and showed average age of 36 years old (9).

Females of reproductive age are most commonly affected by desmoid tumor, which is most probably due to hormonal changes related to the trauma of cesarean sections (10).

Most of the patients with aggressive fibromatosis (desmoid tumor) presented abdominal mass or extremity mass. In our patients, the clinical presentation was very similar to previous reports (10). 
The gold standard and final method of diagnosis is always pathological findings after operation, however, imaging studies such as ultrasonography, Computerized-Tomography (CT) scan and magnetic resonance imaging studies are helpful but not diagnostic (11).

The best method of treatment is excision by surgery. However, adjuvant therapy should be considered for cases with positive surgical margins, multiplicity of the tumor, inoperable tumors, and severe adhesion (12). Another issue in the treatment of fibromatosis is neoadjuvant therapy and chemoradiation before surgery, which is considered in cases with severe adhesion inoperable tumors, and multiple tumors (13). In addition, preoperative chemotherapy has been suggested for head and neck fibromatosis, especially for pediatric age group (14).

The number of published series of fibromatosis for neoadjuvant chemoradiation and also adjuvant therapy after surgery with agents such as cyclophosphamide, doxorubicin, and dacarbazine, are not adequate for a documented therapy and in many reports no recommendation has been made because of young age of the patients and adverse complications $(15,16)$. Treatment of the patients with tamoxifen, tamoxifen analogues, and medroxyprogesterone acetate, has been also recommended in a few case reports (17). None of our cases received chemoradiation.

\section{Conclusion}

Aggressive fibromatosis is a rare disease with many controversies, especially regarding treatment options; more case series with longer follow up is necessary for better decision making about treatment protocols.

\section{Acknowledgment}

This manuscript was extracted from project: No 1895 (Shiraz University of Medical Sciences).

\section{Conflict of Interest}

The authors declare that there was no conflict of interest.

\section{References}

1. Kumar V, Khanna S1, Khanna AK1, Khanna R. Desmoid tumors: Experience of 32 cases and review of the literature. Indian J Cancer 2009 ; 46: 36-9.

2. Kallam AR, Ramakrishna BV, Roy GK, Karthik KRV. Desmoid tumours: our experience of six cases and review of literature. J Clin Diag Res 2014;8: NE01-NE04.

3. Mitchell G, Thomas JM, Harmer CL. Ggressive fibromatosis: evidence for a stable pahse. Sarcoma 1998;2:149-154.

4. Akhavan A, Binesh F, Kargar K, Navabi H. Juvenile female with chest wall fibromatosis located posteriorly to the right breast: radiation therapy or wait and watch? BMJ Case Rep 2013; 113:1-3

5. Ghazipour A, Lahiji SG, Bradd B, Saleheh F. Huge facial desmoid tumors with neck extension: A case report. Iran J Otorhinolaryngol 2014;26: 191-4.

6. Tolan S, Shanks JH, Loh MY, Taylor B, Wylie JP. Fibromatosis: benign by name but not necessarily by nature. Clin Oncol (R Coll Radiol) 2007;19:31926.

7. El-Haddad M1, El-Sebaie M, Ahmad R, Khalil E, Shahin M, Pant R, Memon M, Al-Hebshi A, Khafaga Y, Al-Shabanah M, Allam A. Treatment of aggressive fibromatosis: the experience of a single institution.Clin Oncol (R Coll Radiol) 2009;21:77580 .

8. Meazza C, Bisogno G,Gronchi A, Fiore M, Cecchetto G, Alaggio R, Milano GM, Casanova M, Carli M, Ferrari A. Aggressive Fibromatosis in Children and Adolescents. The Italian Experience. Cancer 2010;1: 233-40.

9. Bertani E, Chiappa A, Testori A, Mazzarol G, Biffi R, Martella S, Pace U, Soteldo J, Vigna PD, Lembo R, Andreoni B. Desmoid tumors of the anterior abdominal wall: results from a monocentric surgical experience and review of the literature. Ann Surg Oncol. 2009 ;16:1642-9.

10. Aghili H, Moghadam MG. Hereditary Gingival Fibromatosis: A Review and a Report of a Rare Case. Case Reports in Dentistry 2013; Article ID 930972, 4 pages.

11. Bolke E, Krasniqi h, Lammering G, Engres R, Mtuschek C, Gripp S, et al. Chest wall and intrathoracic desmoid tumors: Surgical experience and review of the literature. Eur J Med Res 2009 14: 240-243.

12. El-Haddad M, El-Sebaie M, Ahmad R, Khalil E, Shahin M, Pant R, Memon M, Al-Hebshi A, Khafaga Y, Al-Shabanah M, Allam A. Treatment of aggressive fibromatosis: the experience of a single institution. Clin Oncol (R Coll Radiol) 2009 ;21:77580 . 
13. Sharma A, Ngan BY, Sándor GK, Campisi P, Forte V. Pediatric aggressive fibromatosis of the head and neck: a 20-year retrospective review. J Pediatr Surg 2008 ;43:1596-604.

14. Ayala AG, Ro JY, Goepfert H, Cangir A, Khorsand J, Flake G. Desmoid fibromatosis: a clinicopathologic study of 25 children. Semin Diagn Pathol $1986 ; 3: 138-50$.

15. Ramamurthy R, Arumugam B, Ramanandham B. Recurrence Patterns and Management Options in Aggressive Fibromatosis. Indian J Surg Oncol 2012;13:222-227.
16. Micke O, Seegenschmiedt MH; German Cooperative Group on Radiotherapy for Benign Diseases. Radiation therapy for aggressive fibromatosis (desmoid tumors): results of a national Patterns of Care Study. Int J Radiat Oncol Biol Phys 2005;61:882-91.

17. Pafel SR, Evans HL, Benjamin RS. Combination Chemotherapy in Adult Desmoid Tumors. CANCER December 1993;72; 3244-7.

\section{How to Cite This Article:}

Geramizadeh B, Jalali F. Aggressive Fibromatosis, Clinicopathologic Findings of 25 Cases; A SingleCenter Experience and Review of the Literature. Iranian Journal of Pathology. 2017:20-24. 